ments in the hope that younger scientific men in particular may be assisted thereby to improve the writing of scientific papers.

Comments of scientific societies on a recommendation that funds should be made available to provide facilities for the work of editors and publication boards have led the Committee to recommend to the Council of the Royal Society that efforts should be made to obtain an increase in the Parliamentary grant-in-aid of scientific publications administered by the Society, and to extend its scope to cover additional editorial staff and facilities as well as printing costs. The Biological Council has been invited to report on the effectiveness of its calling together the editors of periodicals dealing with the biological sciences with a view to similar collaboration elsewhere, but the suggestion regarding the publication of précis journals was not welcomed. The action taken in regard to fair copying has already been reported in Nature $(164,289 ; 1949)$.

The Abstracting Services Committee believes that improvement is possible in the preparation of authors' summaries or synopses, and has accordingly prepared a leaflet, "Guide for the Preparation of Synopses", which has been sent to scientific societies and other publishers of scientific journals with two recommendations endorsed by the Council of the Royal Society. These recommendations, that every paper in a scientific journal should be accompanied by a synopsis or précis, independent of the text and figures, and preferably at the beginning of the paper, and that these synopses should be subject to the same editorial scrutiny and correction as the full paper, have been copied by Unesco, and the leaflet has been in extensive demand. The Committee also supervised the compilation of a comprehensive list of journals, etc., containing abstracts, and this was issued in June 1949 (see Nature, 164, 692; 1949). The British delegation to the Unesco Conference on Scientific Abstracting consisted of Dr. C. H. Desch, Dr. L. H. Lampitt and Mr. H. T. Pledge, and at the Conference the suggestion that the model of the Abstracting Services Committee should be followed elsewhere was adopted. Following a survey of the practice of more than one hundred British abstracting journals, the Abstracting Services Committee is inviting all abstracting agencies to co-operate towards the general adoption of a standard method of quoting references which the Committee has drafted. Consultation with scientific societies also showed that many societies which do not at present publish the titles of new papers accepted for publication before the papers appear in print have indicated their intention to do so in the future.

The Information Services Committee has also formed a sub-committee under the chairmanship of Prof. J. D. Bernal for further study of classification, but while a specific recommendation relating to the evaluation of new alternative systems of chemical notation has been referred to the International Union of Pure and Applied Chemistry, no significant developments are reported in mechanical methods of indexing and selection. The recommendation that the Publishers' Association be invited to arrange the issue of suitable unit catalogue cards for all British scientific and technical books is considered to have been satisfied by the scheme to be introduced by the British National Bibliography. The Committee is unable to act directly on most of the recommendations relating to aids for information services but has forwarded them to the authorities concerned. Thus, the Federation of British Industries was invited to prepare a directory of industrial research, and the Department of Scientific and Industrial Research to issue a directory of centres of highly specialized research. The Committee has accepted the recommendation of the Panel on Technical Information Services that compilation and publication of a comprehensive index of research activities and specialized knowledge of individual scientific workers is inadvisable at present. An exhaustive study of the need for improved special dictionaries and the fixing of interlingual equivalents for scientific terms has been made by Dr. J. E. Holmstrom, and the results are incorporated in a report issued by Unesco. In this report, which is provided with a bibliography giving particulars of $\mathbf{5 5 0}$ interlingual dictionaries, Dr. Holmstrom suggests that the efforts at present being made to standardize technical terms should be co-ordinated under an International Terminological Bureau to be established by Unesco which, besides conducting research, would maintain relations with all the federations and societies concerned and provide central services. The Bureau would collect and index definitions and technological equivalents which have been used or proposed by individual translators but have not yet been included in known dictionaries, and would issue them to inquirers on demand. It would also offer such definitions and equivalents for official approval as occasion arose, and the approved definitions and equivalents when printed would be distinguished by a suitable symbol to indicate this official approval.

The Information Services Committee has experimental evidence of the value of an agency equipped with special typing facilities, and warmly supports a proposal which has been submitted to the Royal Society, especially for dealing with the acute letter. press difficulties that arise in the field of mathematicsThe Committee decided to delay action on the recommendation that permanent relations be established with representative printing organisations until the effect of improvements which had reduced the delays in the publication of original scientific papers could be assessed, but has recommended the formation of a small consultative committee with representatives from the British Federation of Master Printers and the Printing and Kindred Trades Federation. It has also encouraged the publication of an article on photographic methods of documentary reproduction, and recommended that the Department of Scientific and Industrial Research should initiate and encourage research on methods of photo-copying which do not require the use of silver salts, and especially of methods making it possible to obtain reductions and enlargements.

\section{SUPPLY AND DEMAND FOR PROFESSIONAL ELECTRICAL ENGINEERS}

A

GROUP of sub-committees under the general direction of the Technical Personnel Committee has been engaged for a period of some two years in carrying out a comprehensive survey of the probable future demands in Great Britain for professional personnel in the various branches of science and engineering. The report of the Electrical Engineers' Panel of the Engineering Sub-Committeo has recently been published (London: H.M. Stationery Office, 
6d. net). The Panel was under the chairmanship of Sir Arthur Fleming, who has an intimate personal knowledge of the employment of professional elec. trical engineers in manufacturing industry extending over a long period.

The scope of the investigation covered the assessment of the requirements of the main divisions of the profession and a comparison of this estimate with the existing supply. The estimated annual demand over the next five years is summarized as follows.

Public service (including the Armed Forces, government departments and public bodies such as the National Coal Board and British Electricity Authority

Industry (including research associations)

Teaching (universities and technical colleges)

Emigration and miscellaneous

The annual supply up to 1950 is estimated at 1,550 , made up as follows.

University output

From full-time courses in technical colleges

Higher National Certificates (credit standard)

Miscellaneous (including entry by the examinations of the Institution of Eloctrical Engineers)

660

\section{.}

$\overline{1,550}$

There is thus an estimated annual deficiency of the order of ten per cent. It is concluded that, as there is good ground for expecting an increase of output from the universities and technical colleges, resulting in the main from the substantial building programme which is in progress and the increase in the number of available scholarships, the deficiency is likely to be met by the provisions already in hand. The opinion is expressed that the requirements of industry generally "tended to be higher in the immediate future than was likely to be the case in subsequent years".

While the report is concerned specifically with professional engineers, an interesting incidental comment is made in regard to technicians. In general terms, the distinction between the professional engineer and the technician is made in respect of the professional engineer's ability to take personal responsibility for development in electrical engineering, while the technician will normally carry out technical work in accordance with established practice or under direction. It is estimated that the average ratio of the number of technicians to the number of professional engineers will be of the order of five to one. The report does not consider the adequacy of the supply of technicians, but it may be remarked in passing that there is evidence of a distinct shortage of this class of personnel.

While, as the report points out, no claim can be made for the accuracy of the estimates given, this document constitutes a valuable summary of informed opinion upon an important subject.

\section{CORRECTED KRYPTON WAVE- LENGTHS}

By Dr. T. A. LITTLEFIELD

King's College, Newcastle upon Tyne, I

I USED a reflecting echelon to measure vacuum wave-lengths of thirty-one lines in the arc spectrum of krypton in terms of the cadmium red standard ${ }^{1}$. The dispersion formula of Barrell and Sears ${ }^{2}$ and of Perreau for pure air and carbon dioxide respectively were used to calculate the wave-lengths in 'normal' air (air at $15^{\circ} \mathrm{C}$. and $760 \mathrm{~mm}$. pressure containing
0.03 per cent carbon dioxide). These were found to differ appreciably from those recommended by the International Astronomical Union, although very close agreement was obtained when the dispersion formula due to Kosters and Lampe or Perard ${ }^{5}$ was employed. Barrell and Bruce have pointed out that this discrepancy lies outside the error which could be attributed to difference between the three dispersion formulæ, and further examination has revealed an arithmetical error in the application of the dispersion formula of Barrell and Sears.

The amended wave-lengths in 'normal' air are tabulated herewith, being calculated by each of the three dispersion formula. Where the International Astronomical Union wave-lengths are not available, Jackson' $s^{6}$ are quoted and marked $(J)$ accordingly. For simplicity, only fractional portions of wavelengths are given in the last three columns. Each formula leads to a slightly different primary vacuum wave-length standard, since the wave-length of the cadmium red line 6438.4696 is specified in 'normal' air. Corresponding changes appear in the vacuum wave-lengths, and these are used in calculating the 'normal' air wave-lengths appropriate to each formula.

It will be observed that when the calculation is carried out in this way, differences between 'normal' air wave-lengths obtained by each of the three dispersion formula do not differ by more than three in the fourth decimal place of an Angstrom unit. The mean difference between these wave-lengths and those of the International Astronomical Union is $+0.0003 \mathrm{~A}$., which is the order of the standard deviation of the vacuum wave-length measurements.

This work is being repeated using a more refined technique and at the same time being extended into the near ultra-violet. I am most grateful to $\mathrm{Mr}$. H. Barrell, of the National Physical Laboratory, Teddington, and to Mr. C. F. Bruce, of the Australian National Standards Laboratory, Chippendale, N.S.W., for their assistance in this matter.

\begin{tabular}{|c|c|c|c|}
\hline $\begin{array}{l}\text { International } \\
\text { Astronomical Union }\end{array}$ & $\begin{array}{l}\text { Barrell and } \\
\text { Sears }\end{array}$ & $\begin{array}{c}\text { Kosters and } \\
\text { Lampe }\end{array}$ & Perard \\
\hline $\begin{array}{l}4273 \cdot 9700 \\
4282 \cdot 9683 \\
4286 \cdot 4873 \\
4300 \cdot 4877 \\
4318 \cdot 5525 \\
4319 \cdot 5797 \\
4351 \cdot 3607 \\
4362 \cdot 6423 \\
4376 \cdot 1220 \\
4399 \cdot 9670 \\
4425 \cdot 1906(\mathrm{~J}) \\
4453 \cdot 9179 \\
4463 \cdot 6903 \\
4502 \cdot 3547 \\
5562 \cdot 2257 \\
5570 \cdot 2895 \\
5580 \cdot 388(\mathrm{~J}) \\
5649 \cdot 5628 \\
5672 \cdot 4519(\mathrm{~J}) \\
5707 \cdot 512(\mathrm{~J}) \\
5832 \cdot 859(\mathrm{~J}) \\
5866 \\
5870 \cdot 9158 \\
5879 \cdot 9000(\mathrm{~J}) \\
5993 \cdot 8503 \\
6012 \cdot 1570(\mathrm{~J}) \\
6056 \cdot 1280(\mathrm{~J}) \\
6082 \\
6236 \cdot 354(\mathrm{~J}) \\
6421 \cdot 029 \\
6456 \cdot 291\end{array}$ & $\begin{array}{l}0 \cdot 9703 \\
0 \cdot 9681 \\
0 \cdot 4869 \\
0 \cdot 4861 \\
0.5528 \\
0.5805 \\
0 \cdot 3603 \\
0 \cdot 6420 \\
0 \cdot 1226 \\
0 \cdot 9673 \\
0 \cdot 1904 \\
0 \cdot 9183 \\
0 \cdot 6908 \\
0 \cdot 3549 \\
0 \cdot 2279 \\
0 \cdot 2902 \\
0 \cdot 3888 \\
0 \cdot 5627 \\
0 \cdot 4512 \\
0 \cdot 5127 \\
0 \cdot 8599 \\
0 \cdot 7514 \\
0 \cdot 9168 \\
0 \cdot 9003 \\
0 \cdot 8513 \\
0 \cdot 1569 \\
0 \cdot 1274 \\
0 \cdot 8629 \\
0 \cdot 3519 \\
0 \cdot 0285 \\
0 \cdot 2910\end{array}$ & $\begin{array}{l}0.9703 \\
0.9681 \\
0.4869 \\
0 \cdot 4861 \\
0.5528 \\
0.5805 \\
0.3604 \\
0 \cdot 6422 \\
0 \cdot 1227 \\
0.9674 \\
0 \cdot 1905 \\
0 \cdot 9184 \\
0 \cdot 6908 \\
0 \cdot 3550 \\
0.2280 \\
0 \cdot 2903 \\
0 \cdot 3890 \\
0 \cdot 5628 \\
0 \cdot 4514 \\
0 \cdot 5128 \\
0 \cdot 8600 \\
0 \cdot 7514 \\
0 \cdot 9169 \\
0 \cdot 9005 \\
0 \cdot 8514 \\
0 \cdot 1571 \\
0 \cdot 1275 \\
0 \cdot 8630 \\
0 \cdot 3520 \\
0 \cdot 0285 \\
0 \cdot 2910\end{array}$ & $\begin{array}{l}0.9704 \\
0.9682 \\
0.4870 \\
0.4862 \\
0.5529 \\
0.5806 \\
0.3605 \\
0.6423 \\
0.1229 \\
0.9675 \\
0.1906 \\
0.9185 \\
0.6909 \\
0.3552 \\
0.2281 \\
0.2904 \\
0.3891 \\
0.5629 \\
0.4515 \\
0.5129 \\
0.8601 \\
0.7515 \\
0.9170 \\
0.9005 \\
0.8515 \\
0.1571 \\
0.1270 \\
0.8630 \\
0.3521 \\
0.0285 \\
0.2910\end{array}$ \\
\hline
\end{tabular}

1 Littleffeld, T. A., Proc. Roy. Soc., A, 187, 220 (1946).

Barrell, H., and Sears, J. E., Phil. Trans., A, 238, 1 (1939).

- Perreau, Ann. Chim. (Phys.), (7), 7, 289 (1896).

- Kosters, W., and Lampe, P., Phys. Z., 35, 223 (1934).

- Perard, A., Trav. Bur. Int. Poids et Mes., 19, 66 (1934).

- Jackson, C. V., Phil. Trans., A, 236, 1 (1936). 